\title{
Comparison of Chemical Elements on Carious \& Normal Premolar's Enamel Layers Using Energy Dispersive X Ray Spectrometer (X Ray-EDS)
}

\author{
A. Adabache-Ortiz ${ }^{1}$, M. Silva-Briano1, M. R. Campos-Esparza², J. Ventura-Juárez ${ }^{2}$ \\ ${ }^{1}$ Departamento de Biología, Laboratorio de Microscopía de Alta Resolución del Centro de Ciencias Básicas, \\ Universidad Autónoma de Aguascalientes, Aguascalientes, México \\ ${ }^{2}$ Departamento de Morfología, Universidad Autónoma de Aguascalientes, Aguascalientes, México \\ Email: ${ }^{*}$ jventur@correo.uaa.mx
}

Received 24 August 2014; revised 18 September 2014; accepted 17 October 2014

Copyright (C) 2014 by authors and Scientific Research Publishing Inc.

This work is licensed under the Creative Commons Attribution International License (CC BY).

http://creativecommons.org/licenses/by/4.0/

(c) (i) Open Access

\begin{abstract}
Objectives: To compare the distribution of chemical elements among the carious and normal enamel layers on teenagers, using energy dispersive $X$ ray spectrometer (EDS Rx). Materials and Methods: The EDS Rx analyzer is integrated to scanner electron microscope. The macro and microelements were made in 30 premolars of teenager: 14 carious enamel layers and 16 normal enamel layers. Results: The quantitative and qualitative microanalyses of macro and microelements were found between the enamel layers of carious and normal premolar in term of variation and concentration expressed in percentage atomic weight. The statistical data analysis of ANOVA showed that the macroelements $[\mathrm{C}, \mathrm{Ca}, \mathrm{P}]$ and the microelements $[\mathrm{Al}, \mathrm{Cl}, \mathrm{Mg}, \mathrm{Na}]$ were significantly different $(P<0.05)$ while, the macro [0] and the microelements [ $\mathrm{In}, \mathrm{Si}, \mathrm{W}, \mathrm{S}]$ were not significantly different $(P<0.05)$ among the carious and normal enamel layers. Moreover, the microelements $\mathbf{S b}$, $\mathrm{Ba}, \mathrm{Br}, \mathrm{I}, \mathrm{Ir}, \mathrm{K}, \mathrm{Pt}, \mathrm{Sc}, \mathrm{Sr}$, Sn and $\mathrm{Yb}$ were absent in carious enamel layers and present in normal enamel layers. Conclusion: The macro and microelements differ in composition and variation from the external to the internal enamel layers between the carious and the normal premolars. However, the deficiency or excess of these elements in the enamel layers determines the degree of susceptibility to carious and other dental disease. Clinical Relevance: The carious enamel in dental structure could be a major dental problem due to the deficiency or excess of macro and microelements which are responsible for secondary or recurrent caries, discoloration, pulpal inflammation, re-infection, abscess in jaw bone and dental disease.
\end{abstract}

${ }^{*}$ Corresponding author.

How to cite this paper: Adabache-Ortiz, A., Silva-Briano, M., Campos-Esparza, M.R. and Ventura-Juárez, J. (2014) Comparison of Chemical Elements on Carious \& Normal Premolar's Enamel Layers Using Energy Dispersive X Ray Spectrometer (X Ray-EDS). Microscopy Research, 2, 81-91. http://dx.doi.org/10.4236/mr.2014.24010 


\section{Keywords}

\section{Microelements, Enamel, Premolar, Caries, EDS Rx}

\section{Introduction}

The teeth are joined to the maxillary mainly by the specialized support apparatus which have alveolar bone, periodontal ligament and cements; all of them are protected by gum. The crown and more than one root bellow the gum, hold the teeth in bony sockets called alveoli, one for each tooth [1] [2]. The teeth are composed by anatomic crown covered by endure and fragile enamel, in which it is the most highly mineralized substance of the body and is composed of parallel prisms arranged perpendicularly to the surface of the enamel [3]; the enamel prisms are formed by a highly calcified material cemented, forming a tightly packed mass of hydroxylapatite crystals (crystalline calcium phosphate) in an organized pattern [1]. Also, enamel has two unique classes of proteins called amelogenins and enamelins that probably cooperate together in macromolecular self-assembly and in controlling enamel mineral formation [4]. The elements contents of Fluorine (F), Iodine (I), Strontium (Sr), and Molybdenum (Mo) are included in the crystals of hydroxyapatite or during the enamel formation [5]. Moreover, several trace elements are included in dental enamel like, $\mathrm{Na}, \mathrm{Cl}, \mathrm{Mg}, \mathrm{K}, \mathrm{S}, \mathrm{Zn}, \mathrm{Sr}, \mathrm{F}, \mathrm{Fe}, \mathrm{Al}, \mathrm{Pb}, \mathrm{B}$, $\mathrm{Ba}, \mathrm{Cu}, \mathrm{Rb}, \mathrm{Br}$, Mo, Sd, I, Ti, Mn, Cr, Sn, Ni, Li, Ag, Ng, Sc, Be, Zr, Co, W, Sb, Hg, As, Cs, Pr, Nd, Sm, Tb, Y, Se, Ga, Ge, Ru, Pb, In, Te, Eu, Gd, Dy, Ho, Er, Tm, Lu, Hf, Ta, Re, Os, Ir, Pt, Bi and Rh. The effect of these elements in the highest or lowest amount on dental caries is probably by altering the resistance of the teeth itself or by modifying the local environment or the chemical and physical composition of the teeth thus affecting the solubility of the enamel to acid attacks [6]. However, most of the organic and inorganic minerals are allotted in whole teeth [7]. The enamel is composed mostly by $96 \%$ of minerals, $1.8 \%$ organic matter and $3.2 \%$ water [8]. Although, we must take into account that the major or minor ratio of minerals in the teeth will depend on the pattern distribution of several factors such as: 1) the geographic region, 2) the underground water and superficial water, 3) the type of food, 4) the physical abrasion, 5) the application of mechanical strength, 6) the age, 7) the oral care and its hygiene, and latter, 8) the kind of medicine, and 9) environmental influence; these factors can influence the prevailing of some minerals on the teeth [1] [9].

The enamel superficial layers suffer the effect of the chewed strength transmitted to the deepest layers which induce change with the age. The components of superficial layer provoke modification due to ionic interchange in the oral medium [10]. However, during the daily work of the teeth the enamel is exposed to suffer diverse strengths which are mechanical and physical abrasion, microbiological degrade, excess or deficiency of trace elements (caries), and/or fracture [11] [12]; for this reason it is necessary to study the regional content of chemical elements between carious and normal premolar enamel layers and its relation.

\section{Materials and Methods}

\subsection{Studied Area of the Dental Enamel.}

We studied 14 carious enamel and 16 normal enamel from 30 premolar of teenagers. We chose 17 points distributed around the three enamel layers (Figure 1), each point from 17 points of carious and normal premolar layers, is taken and analyzed from the EDS X ray of the Scanner Electron Microscope (SEM) (Figure 2). The external layer comprised the points 2, 7, 10, 13 and 16; the mid layer considered the points, 3, 6, 9, 12 and 15; finally the internal layer included the points 1, 4, 5, 8, 11, 14 and 17 (Figure 1).

\subsection{Treatment and Assemblage of the Sample}

30 premolar enamel layers were studied and analyzed by EDS X ray to compare the different element content of normal and carious enamel layers (Figure 1). The premolar were polished along their longitudinal plane on both sides using water and fine sharpening stone (Electron Microscopy Sciences catalog 62082-10) to obtain a thinner samples about $4 \mathrm{~mm}$ thickness. After, they were washed with distillated water and set up for 5 minutes in Bransonic ultrasonic cleaner, brand 1510 Branson, to remove the excess of adhesive particles. The dental pieces were dried at $37^{\circ} \mathrm{C}$ for 3 days in one incubator. Latter, each one of these was pasted on the graffito over each 

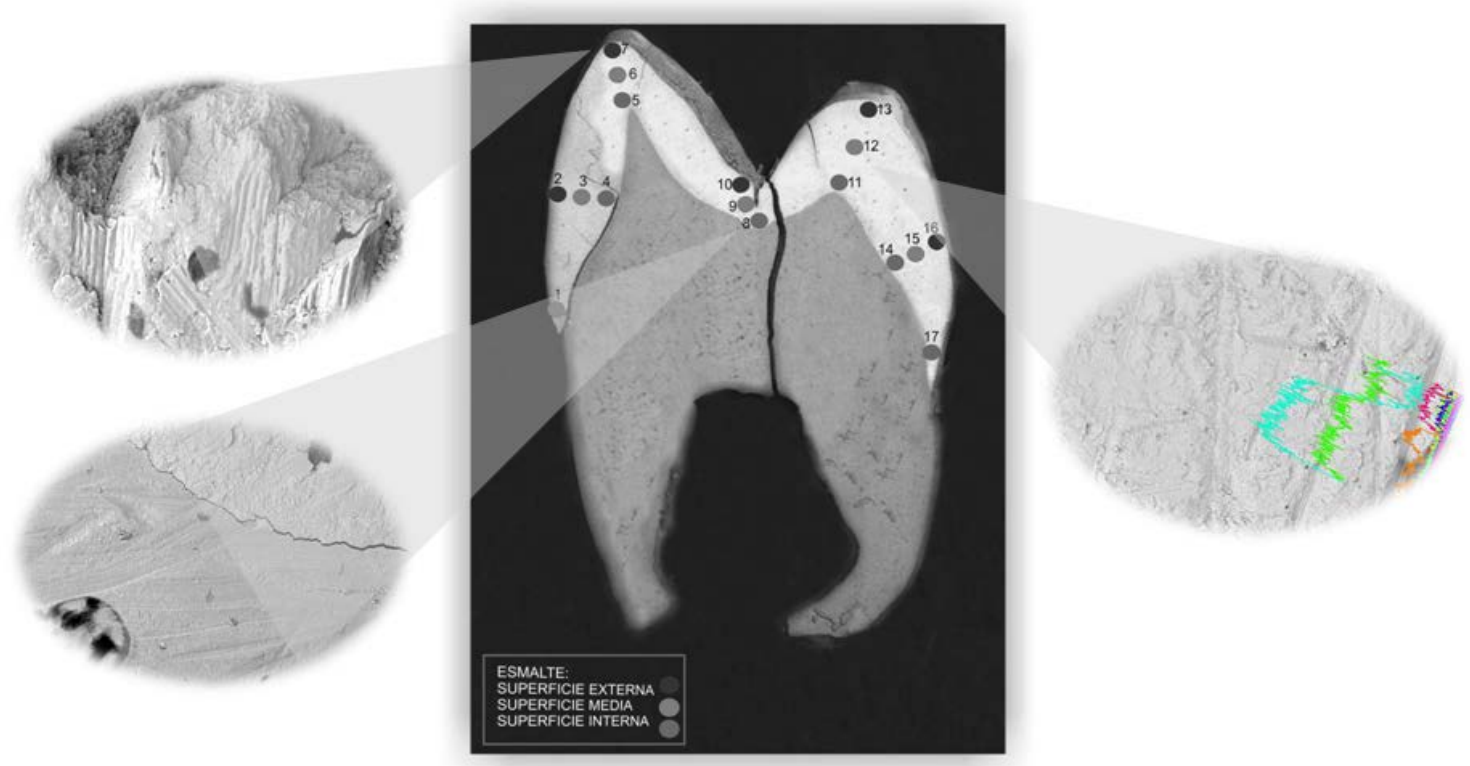

Figure 1. Analyzed points around the carious and normal enamel layers on the premolar and its elements per point made by EDS X ray.
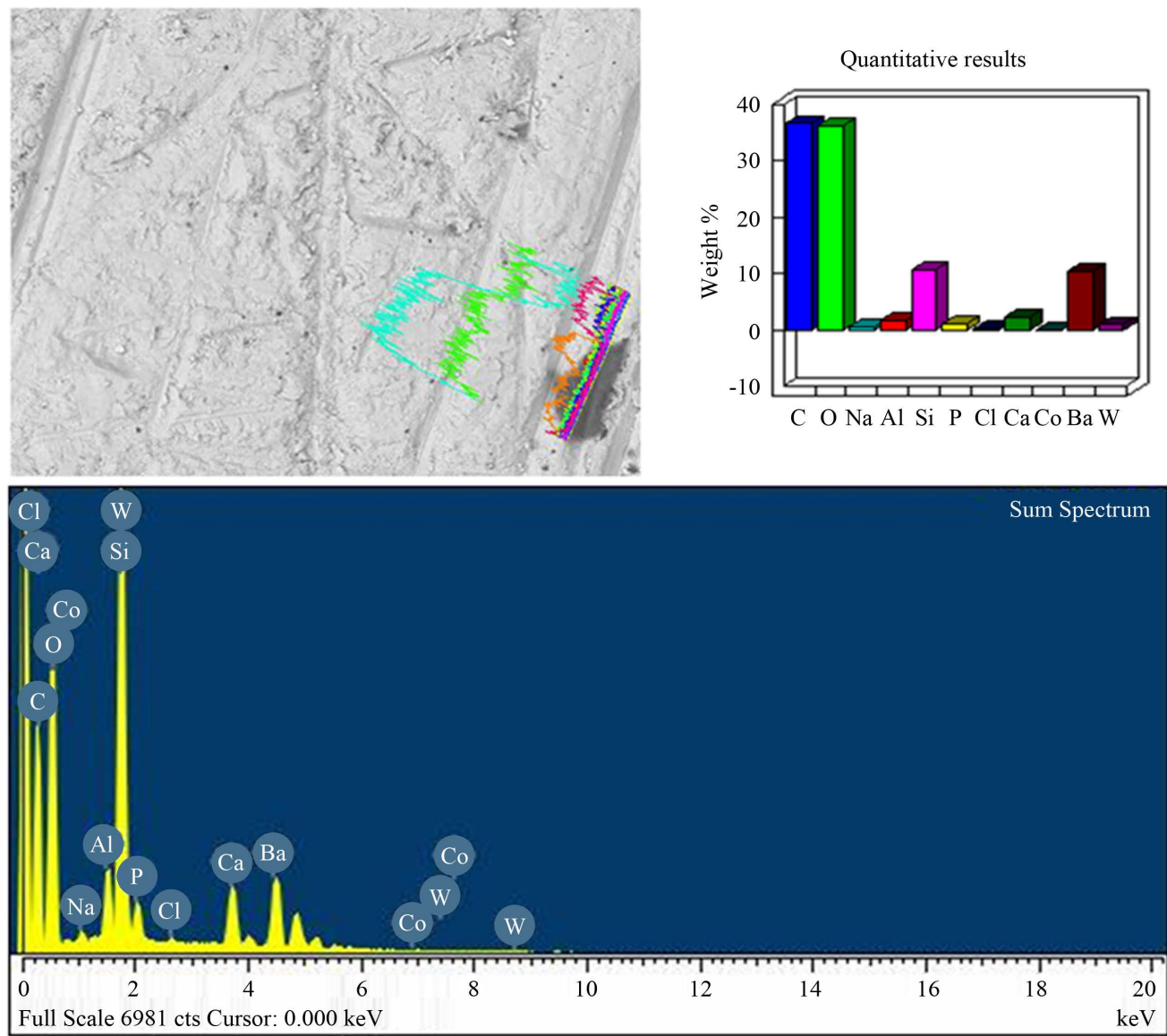

Figure 2. The top photograph shows the distribution of different elements in one of the points marked with the method one line by EDS X ray. These are displayed in the spectral graph (bottom) and reported in the bar graph (top left). 
stub. Finally they were coated with coal by the Dentum Vacuum III device.

\subsection{Analysis of Permanents Premolars on X Ray-EDS}

The samples were observed under optimum conditions in Scanner electron microscope at $20 \mathrm{Kv}$ accelerating voltage, the working distance was $10 \mathrm{~mm}$, the magnification was around $600 \times$ and the examining spot diameter was $20 \mu \mathrm{m}$ (Figure 2). The EDS Rx analyzer had probe current $10 \mathrm{eKv}$ energy scale and 200 sec counting time under these conditions, it is sufficient to obtain integral spectral values (see an example of Figure 2). The employed method was one line between two points of interest on the sample to obtain the qualitative and quantitative trace elements in each randomly selected point of interest on the premolars enamel (Figure 2). The results were obtained by EDS Rx INCA Software Suite Version 3.04, resolution 3 nm, Oxford Instruments Analytical Limited 2001. The system number was 10062 [13] [14].

\subsection{Statistical Analysis of Premolars Samples}

Statistical data analysis of one way ANOVA are chosen to compare the significant difference $(p<0.05)$ of macro and microelements (\% atomic weight) between the enamel layers of carious and normal premolar which are calculated using the statistical program Prism. The results were reported in Table 1.

\section{Results}

The results showed the qualitative and quantitative microanalysis of the pattern distribution and concentration of macro and microelements which, were identified around the enamel layers of 30 premolars on teenager (Figure 1). 14 Carious enamel layer $(n=14)$ showed a full record of 4 macroelements of $C$, Ca, O and $P$, and 8 microelements of $\mathrm{Al}, \mathrm{Cl}, \mathrm{In}, \mathrm{Mg}, \mathrm{Si}, \mathrm{Na}, \mathrm{S}$ and $\mathrm{W}$ whereas, 16 normal enamel layer $(\mathrm{n}=16)$ detected 4 macroelements of C, Ca, O and P and 18 microelements of Al, Sb, Ba, Br, Cl, I, In, Ir, Mg, K, Pt, Sc, Si, Na, Sr, Sn, W and Yb used the microanalysis Energy Dispersive Spectrometer X ray (EDS Rx) (see Table 1). In Figure 2 one of the microphotograph showed the distribution of different chemical elements in several color lines of the chosen point of interest of the enamel layer. These are displayed in the spectral graph and reported too as a bar graph. The distribution and variation of these elements were different in term of concentration to carious premolar with respect to normal premolar (Table 1 ).

The statistical data analysis of one way ANOVA showed in Table 1, the macro and microelements marked with asterisk $\left(^{*}\right)$ in which they were significant different $(p<0.05)$ among the three enamel layer of carious and normal premolar. These macro and microelements are expressed in percentage atomic weight. The macroelements Carbon (C), Phosphorus (P) and Calcium (Ca) were significantly different $(p>0.05)$ in carious enamel layers than in normal enamel layer. However, Carbon (C) was significantly higher in the external and mid enamel layer while, Phosphorus (P) and Calcium (Ca) were significantly lower in carious enamel layers in comparison to normal enamel layers. The Oxygen $(\mathrm{O})$ did not modify in both enamel layers of carious and normal premolar.

Moreover, the Aluminium (Al), Chlorine (Cl), Sodium (Na) and Magnesium (Mg), were significantly different $(p<0.05)$ in carious enamel layers than in normal enamel layer. The Al microelement is significantly $(p<$ 0.05 ) lower in carious enamel layers whereas, Na increased remarkable in the external and increased slightly in the mid enamel layer, as well as $\mathrm{Cl}$, also, increased slightly in the external and internal enamel layer, and Magnesium (Mg) too, in the mid enamel layer of carious premolar in regard to normal enamel layers (see Table 1). On the other hand, the Silicon (Si) was not significant different $(p<0.05)$ in carious and normal enamel layer, neither, Tungsten (W), even if W microelement have seen much lower and Si slightly higher in carious enamel layers with respect to normal enamel layers. In addition, the Sulfur (S) microelement was not significant different $(p<0.05)$ in the external layers of carious and normal enamel, neither the mid and internal layers of normal premolar due to its absence. None, the Indium (In) microelement was significantly different $(p<0.05)$ in the mid layer of carious and normal premolar. Despite, we should consider that the microelements Antimony (Sb), Barium (Ba), Bromine (Br), Iodine (I), Iridium (Ir), Potassium (K), Platinum (Pt), Scandium (Sc), Stronium (Sr), Tin $(\mathrm{Sn})$, Ytterbium $(\mathrm{Yb})$ were absent in carious enamel layer due to possible demineralization or caries development (see Table 1). 
Table 1. Comparison of total mean of macro and microelements in carious and normal enamel layers from teenagers using one way ANOVA. The asterisk $\left(^{* * *}\right)$ means significantly different $(p<0.05)$ from carious enamel to normal enamel layers, expressed in \% atomic weight.

\begin{tabular}{|c|c|c|c|c|c|c|}
\hline \multirow{3}{*}{ ELEMENTS } & \multicolumn{6}{|c|}{ SECOND SUPERIOR PREMOLAR } \\
\hline & \multicolumn{3}{|c|}{ NORMAL ENAMEL (\% ATOMIC WEIGHT) } & \multicolumn{3}{|c|}{ ENAMEL WITH CARIES (\% ATOMIC WEIGHT) } \\
\hline & EL & ML & IL & EL & ML & IL \\
\hline \multicolumn{7}{|c|}{ MACROELEMENTS } \\
\hline Carbono C & $18.86+0.3661^{* * *}$ & $18.37+0.3785^{* * *}$ & $20.02+0.3924$ & $22.90+0.4453$ & $21.22+0.426$ & $20.90+0.3185$ \\
\hline Calcium Ca & $25.7+0.4609$ & $26.15+0.3493$ & $25.27+0.3962$ & $16.98+0.3293^{* * *}$ & $16.92+0.2981$ & $17.45+0.2734^{* * *}$ \\
\hline Oxygen $\mathrm{O}$ & $38.61+0.3964$ & $38.65+0.4392$ & $39.03+0.3748$ & $38.65+0.4392$ & $37.91+0.4090$ & $38.02+0.5004$ \\
\hline Phosphorus P & $12.58+0.1543$ & $12.7+0.1398$ & $12.65+0.1389$ & $9.616+0.1085^{* * *}$ & $9.589+0.1549^{* * *}$ & $9.651+0.09008^{* * *}$ \\
\hline \multicolumn{7}{|c|}{ MICROELEMENTS } \\
\hline Aluminium $\mathrm{Al}$ & $0.1683+0.0081$ & $0.1658+0.0080$ & $0.1582+0.0064$ & $0.134+0.0053^{* *}$ & $0.1271+0.0044^{* * *}$ & $0.1229+0.0032^{* * *}$ \\
\hline Antimony Sb & $0.2842+0.078$ & & & & & \\
\hline Barium $\mathrm{Ba}$ & $0.6046+0.2197$ & $1.011+0.1895$ & $1.263+0.2201$ & & & \\
\hline Bromine $\mathrm{Br}$ & $0.3433+0.0066$ & $0.38+0.064$ & & & & \\
\hline Chlorine $\mathrm{Cl}$ & $0.3735+0.016^{*}$ & $0.3431+0.0153$ & $0.3686+0.059^{*}$ & $0.5119+0.0319$ & $0.4627+0.0288$ & $0.5011+0.0923$ \\
\hline Iodine I & $0.3231+0.0405$ & $0.3193+0.031$ & & & & \\
\hline Indium In & & $0.3765+0.044$ & & & $0.3319+0.042$ & \\
\hline Iridium Ir & & $0.1007+0.0069$ & & & & \\
\hline Magnesium $\mathrm{Mg}$ & $0.32+0.0209$ & $0.2362+0.007$ & $0.2457+0.0196$ & $0.3533+0.015$ & $0.2986+0.009^{*}$ & $0.3013+0.0084$ \\
\hline Potassium K & $0.2805+0.045$ & $0.2038+0.039$ & $0.2004+0.019$ & & & \\
\hline Platinum Pt & & $0.1500+0.028$ & & & & \\
\hline Scandium Sc & $0.2956+0.096$ & $0.2574+0.051$ & $0.27+0.090$ & & & \\
\hline Sílicon Si & $0.3437+0.089$ & $0.3198+0.053$ & $0.3601+0.026$ & $0.3084+0.0502$ & $0.5231+0.1084$ & $0.3937+0.054$ \\
\hline Sodium Na & $0.6435+0.029^{* * *}$ & $0.6493+0.019^{*}$ & $0.7465+0.025$ & $0.8242+0.029$ & $0.7613+0.025$ & $0.7513+0.035$ \\
\hline Stronium $\mathrm{Sr}$ & $1.261+0.063$ & $1.419+0.034$ & $1.188+0.080$ & & & \\
\hline Sulfur S & $0.105+0.005$ & & & $0.1040+0.025$ & $0.138+0.0135$ & $0.1200+0.020$ \\
\hline Tin Sn & $0.4959+0.036$ & $0.4975+0.038$ & $0.6009+0.037$ & & & \\
\hline Tungsten $\mathrm{W}$ & $1.415+0.0074$ & $1.275+0.051$ & $0.93+0.00$ & $1.049+0.093$ & $0.8067+0.1065$ & $1.220+0.1148$ \\
\hline Ytterbium $\mathrm{Yb}$ & $0.3681+0.031$ & $0.3528+0050$ & $0.3433+0.055$ & & & \\
\hline
\end{tabular}

Abbreviations: $\mathrm{EL}$ = External enamel layer; $\mathrm{ML}$ = Mid enamel layer; IN = Internal enamel layer.

Notwithstanding, several elements were found in the spotted or stained enamel layers from 30 normal and carious premolar. Qualitative chemical elements were obtained in the spectral graph of EDS X ray to identify the spotted enamel around the enamel thickness and part of the dentin (see Figure 1). The gray, gray-dark and mixed color were found on carious and normal premolar enamel (see Figure 3). The gray spotted enamel had the macroelements Carbon (C), Calcium (Ca), Phosphorus (P) and Oxygen $(\mathrm{O})$ as well as, the microelements of Magnesium (Mg), Sodium (Na) and Chlorinate $(\mathrm{Cl})$. At the same time, the gray dark spotted enamel obtained the macro-elements of C, Ca, P, O as well as, the microelements of $\mathrm{Mg}, \mathrm{Na}, \mathrm{Cl}, \mathrm{Sr}$, and Si (see Figure 3). Apart of the mentioned elements presented in the gray and gray dark spotted enamel thickness; the elements potassium 

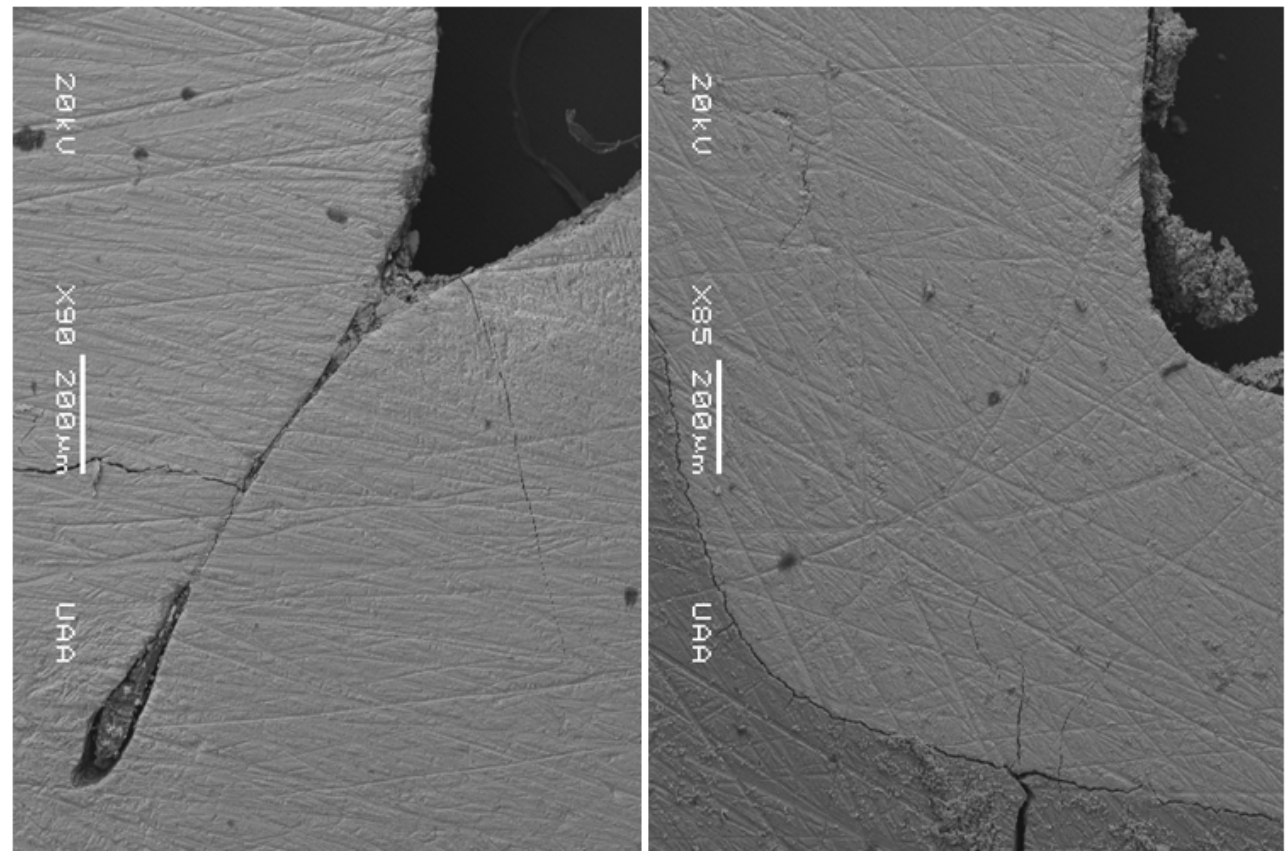

Figure 3. Morphological changes taking place in the surface of carious enamel (left) compared to normal enamel (right) of the premolar.

$(\mathrm{K})$ and barium $(\mathrm{Ba})$ were found on the mixed spotted enamel thickness of carious and normal premolar (see Figure 3).

\section{Discussion}

Different investigators [15]-[25] have found the presence and variation of trace elements and their concentration in the enamel teeth of $\mathrm{C}, \mathrm{O}, \mathrm{Ca}, \mathrm{P}, \mathrm{Na}, \mathrm{Cl}, \mathrm{Mg}, \mathrm{K}, \mathrm{F}, \mathrm{Fe} \mathrm{Ba}, \mathrm{Br}, \mathrm{Al}$, Sr, and occasionally Zn, Pb, Mo, Ni. Only some of the author [6] [16] [26]-[33] have reported the presence and distribution of these elements in normal enamel layer, or enamel thickness as well as the studies of trace elements reported by Rao 2008 (see Introduction above). Some of the mentioned elements coincided with the reported elements in our studies of EDS X ray analysis (Table 1). The qualitative and quantitative analysis EDS $\mathrm{X}$ ray showed the evidence that the lowest content of macro-elements $\mathrm{Ca}, \mathrm{P}, \mathrm{C}, \mathrm{O}$, and microelements of $\mathrm{Al}, \mathrm{Cl}, \mathrm{In}, \mathrm{Mg}, \mathrm{Si}, \mathrm{Na}, \mathrm{S}$ and $\mathrm{W}$ were found in carious enamel layers than in normal enamel layers (Table 1). However, it is remarkable to notice in Table 1 that the microelements Antimony (Sb), Barium (Ba), Bromine (Br), Iodine (I), Iridium (Ir), Potassium (K), Platinum (Pt), Scandium (Sc), Stronium (Sr), Tin (Sn), Ytterbium (Yb) were absent in carious enamel layer but not in normal enamel layers (Table 1). Our results give us an idea that the samples of the premolar differ in composition and variation of the elements between the carious and normal enamel layers, from the external to the internal enamel layer in terms of density and concentration expressed in percentage atomic weight (Figure 1 and Table 1). Dugal reported that the mineral vary from the outer enamel surface toward the interphase dentin enamel and its concentration is greater in the junction dentin-enamel in normal premolar [28] [34] than in carious premolar reported in Figure 1 and Table 1. Most of the elements coincide with the preferential mineralization in the deeper region of the enamel thickness of normal premolar except $\mathrm{Ca}, \mathrm{P}, \mathrm{Al}, \mathrm{Yb}$ and $\mathrm{Sr}$ (Table 1). For the contrary the concentration of $\mathrm{Ca}, \mathrm{P}, \mathrm{Cl}, \mathrm{Mg}, \mathrm{Na}, \mathrm{Si}$ and $\mathrm{W}$ are lower in the mid enamel layer and greater in the internal enamel layer of carious premolar (Table 1). The accumulated chemical elements in the enamel layers of normal premolar are regarded as a good indicator of qualitative changes in the modes of nutrition and public water as the macro-elements $\mathrm{C}, \mathrm{O}, \mathrm{Ca}, \mathrm{P}$, and the microelements $\mathrm{Mg}, \mathrm{Sr}, \mathrm{Na}, \mathrm{Al}, \mathrm{Si}, \mathrm{Cl}, \mathrm{Ba}, \mathrm{K}, \mathrm{Br}$ and $\mathrm{S}$. These are a constituent of all dental tissue for health and wellbeing [33]. However, the chemical element content of Calcium (Ca) and Phosphorus (P) are significantly lower $(p>0.05)$ in carious enamel layers than in normal enamel layers (Table 1). Calcium (Ca) deficiency and generalized malnutrition disturb the physiological conditions that affect amelogenesis in human [35]. It is possible that P too because it works together with Ca to make 
hydroxyapatite crystals. These elements reacts each other and form complex compound which serve to withstanding the force of abrasion erosion and play a role in the ethiopatogenesis of dental caries [30]. In addition, it is well know that apatite phases can apparently be affected by the microelements incorporated into teeth with effects on the physicochemical properties [24]. Carbon (C) is significantly higher $(p<0.05)$ in carious enamel layers than in normal enamel layers except, the internal enamel layer (Table 1). The introduction of $C$ in dental matrix increased the solubility of the enamel and make teeth more prone to decay or causing dental caries [5]. On the other hand, Carbon mineral is needed for remineralization and change back into the solid mineral becoming part of the latticework enamel [25] [35]. This is how our bodies restore naturally minerals leaching out by strong leaching acids, to strengthen and harden our dental enamel using the $\mathrm{CO}_{2}$ from our breathing and minerals in our saliva from our food [36]. The $\mathrm{O}$ was not modified in both carious and normal enamel layers (Table 1). Although, the remineralization produced by hydroxyapatite consists in a deposition of a new apatite mineral into the eroded enamel surface scratches, carious surface [31] [37]. Acid attack is one of the major causes of enamel hydroxyapatite loss [25] [27]. It may occur even in young age as a consequence of plaque metabolism or simply due to food and beverage intakes [25]. Natural remineralization is always taking place [32], offering protection against mechanical damage during dental functions [3], according to the level of activity of the mouth condition.

The $\mathrm{Al}$ microelement is significantly $(p<0.05)$ lower in carious enamel layers than in normal enamel layers. There are indications that aluminum salts can be considered cariostatic [38]. Na is remarkable higher in the external and slightly higher in the mid enamel layer, as well as $\mathrm{Cl}$ too, in the external and internal enamel layer, and Magnesium (Mg), in the mid enamel layer of carious premolar in regard to normal enamel layer (see Table 1). Riyat and Sharma said that lower amount of $\mathrm{Na}$ and $\mathrm{Mg}$ apart of the elements reported in Table 1; indicate the possible role in predisposing or causing dental caries [36]. Na and Mg compounds play a role in the dissolution-precipitation reactions in dental enamel during acid attack [39] [40]. B, Mg in high amount and Sr in low amount indicate toward the possibility to predisposing or causing dental caries [40] [41]. This is why deficiency or excess of F, Sr, Mg and some other trace elements reported in our study (Table 1) are one of the factors which determine the degree of susceptibility to carious and other dental disease [24], if they overgrow the standard value like $\mathrm{S}$ in carious enamel layers. The other remarkable points of view are that Mg plays an important role in crystal growth regulation owing to stabilization of the amorphous form of calcium phosphate in normal premolar [41] [42]. On the other hand, the Silicon (Si) was not significant different $(p<0.05)$ in carious and normal enamel layer, neither, Tungsten (W), even if W microelement have seen much lower and Si slightly higher in carious enamel layers. Curzon [11] has noted that zinc and calcium showed promise as antiplaque agents, whereas Strontium (Sr) and Zinc (Zn) may enhance remineralization in enamel. It is believe that fluoride in the premolar enamel enhance mineral deposition as a result of the mineralized enamel matrix when there is acidification in the oral cavity due to the acid food. Fluoride prevents the dental caries, fortified the bones and promotes the remineralization [35]. Fluoride did not find in normal enamel layers neither, in carious enamel layers (Table 1) because of vanishing of fluoride after premolars extraction or maybe because of the insufficient penetration of incidence beam of EDS X ray. However, fluoride ions generate a surface modification of the natural enamel apatite crystals increasing their crystalline degree and relative mechanical and acid resistance [43]-[45]. The promotion of good oral hygiene and a low sugar diet prevent build-up of plaque and reduce the incidence of tooth decay [17] [46].

However, we should consider that the microelements Antimony (Sb), Barium (Ba), Bromine (Br), Iodine (I), Iridium (Ir), Potassium (K), Platinum (Pt), Scandium (Sc), Stronium (Sr), Tin (Sn), Ytterbium (Yb) were absent in carious enamel layer due to caries development which have been altering the premolar resistance, the topographical change in the surface of carious enamel, the affected lesion to its entire depth in the interface of the crown by increasing the incidence of dark and the surface lost (Figure 3), moreover the microbiological development degree and plaque of bacteria have been reached the interphase dentin enamel, as well as, pulpal inflammation, re-infection and abscess in jaw bone is carried out [47] [48] (Figure 3). The absent of these microelements in carious enamel (Table 1) coincided with Rao [6], as well as the microelements $\mathrm{Al}, \mathrm{Si}$, W which were significantly lower $(p<0.05)$. We have to take into account that likely $\mathrm{Si}$ is a new element found in normal and carious enamel layer and $\mathrm{Yb}$ too but only it was present in normal enamel layers. These microelements were no reported in any consulted literature. However, the lower amount of $\mathrm{Ca}, \mathrm{P}, \mathrm{Na}, \mathrm{Mg}, \mathrm{Zn}, \mathrm{B}$, Mo and F on the enamel teeth indicates towards their possible role in predisposing or causing dental caries [35].

The mechanical strength of filled particles may scratch and abrade the antagonistic enamel in the teeth struc- 
ture and could be a major dental problem that is responsible for cases of secondary or recurrent caries, discoloration as well as pulpal inflammation and re-infection [47] [48]. In addition, the restorative material of resin, porcelain, amalgam, hidroxiapatita crystal, ceramic and other filled material (crystal formation in mineralized tissues induced by calcium phosphate and related bone graft) and cattle bone [49] [50] and C, O, Al, Si, Cu, Zn, $\mathrm{Ag}, \mathrm{Sn}, \mathrm{Hg}, \mathrm{Ti}, \mathrm{Ba}, \mathrm{Zr}$ and Si reproduce not only the aesthetic characteristics of the teeth, but also their physical and biological properties which introduce and shift new elements in our teeth [37] [49] [51]. The dental practitioner must carefully evaluate the probable abrasive effects of using braces, leaching treatment and certain restorative materials like porcelain or resin or Zirconium (Zr), [50] [52] composites to oppose existing tooth structure [44] [45].

Not all the functional mineral elements for human enamel layer of normal and carious premolar have been identified in consulted articles due to scarce information. Moreover, numerous biochemical and genetic functions for trace elements should likely remain to be identified in normal enamel and different kind of diseases apart of caries to give alternative solutions. The determination of the importance of trace elements for human health and well-being should be considered a work in progress with some exciting advances likely in the future because they were incomplete published information about the function and roll of some chemical elements not mentioned that play around the enamel layers of normal and carious premolar.

Additional information of the spotted premolar enamel thickness and dentin are probably impurities of Sodium (Na), Magnesium (Mg), Potassium (K), Lead (Pb), Strontium (Sr), Barium (Ba) and especially Carbonate (C) which is possible introduce defects into hydroxyapatite crystal that render its significantly more [25] (Figure 4). These elements are shown in Table 1 except $\mathrm{Pb}$. Some of the detected element found in the gray spotted enamel (C, Mg, $\mathrm{Na}, \mathrm{Cl}, \mathrm{Sr}, \mathrm{Si}$ ), dark spotted enamel (C, Mg, Na, Cl, Sr and $\mathrm{Si}$ ) and mixed spotted enamel (C, $\mathrm{Mg}, \mathrm{Na}, \mathrm{Cl}, \mathrm{K}, \mathrm{Sr}$ and $\mathrm{Ba}$ ) of the normal and carious premolar coincided with the reported elements of the author except $\mathrm{Ca}$, $\mathrm{P}$ and $\mathrm{O}$ (Table 1). It is also known that hydroxiapatite contain at least trace amounts of other elements like $\mathrm{Na}, \mathrm{Mg}$, Zn, K, Pb, Sr, Fe, and other minor ionic components which can be accommodated within the lattice [25]. On the other hand, several ions like Magnesium (Mg), Fluorine (F), Iodine (I), Strontium (Sr), and Molybdenum (Mo) are included in the crystals of hydroxyapatite or during the enamel formation [5].

\section{Conclusions}

The use of the EDS $\mathrm{X}$ ray result as a specific tool of high definition to detect and assess the qualitative and quantitative concentration of the elements expressed in \% atomic weight on dental enamel thickness in order to compare the diverse allot of elements along the three classified layers of carious and normal premolar enamel.

The results in this study show the evidence that the lower contents of macroelements and microelements were found in carious enamel layer than in normal enamel layer of the premolar. The elements Sb, Ba, Br, I, In, K, Pt, $\mathrm{Sc}, \mathrm{Sr}, \mathrm{Sn}$ and $\mathrm{Yb}$ were absent in carious enamel layer. The In microelement was found in the mid enamel
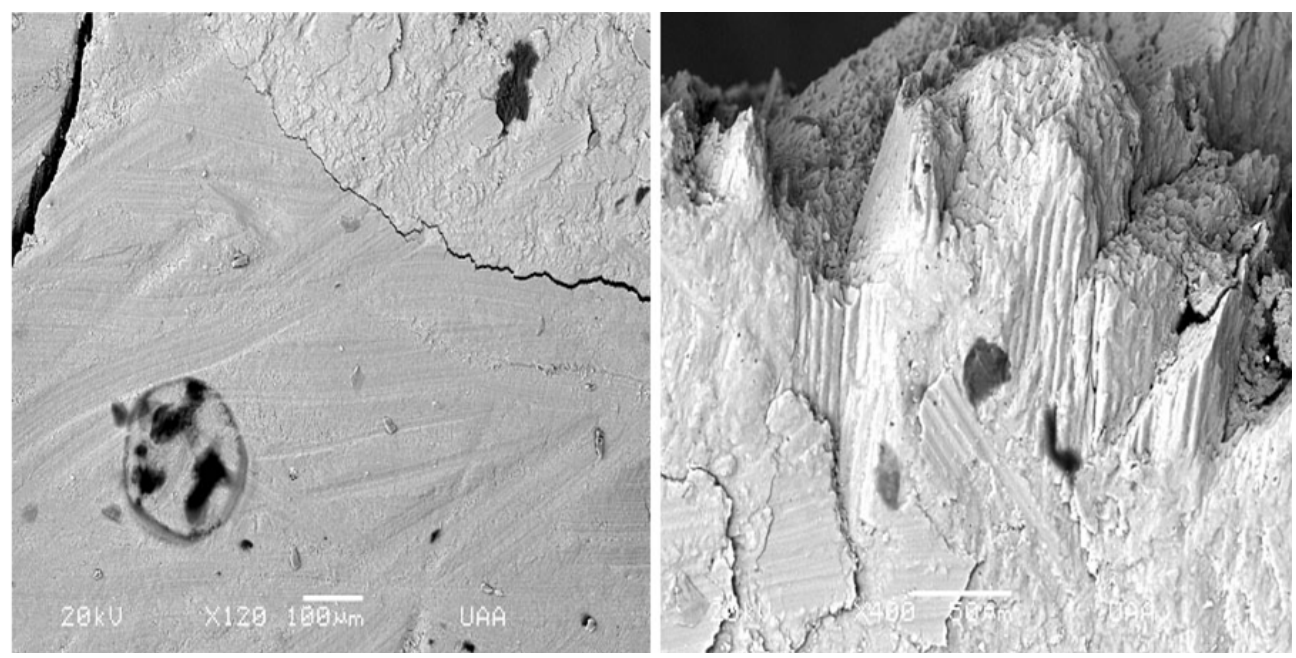

Figure 4. Spotted or stained in premolars carious enamel (left) or in normal enamel layer (right). 
layer of carious and normal enamel as well as $\mathrm{S}$ in the three-enamel layer of carious premolar. It is possible that two new elements of Si and $\mathrm{Yb}$ had appeared in the enamel premolar by the analysis of EDS X ray. They were no reported in the consulted literature.

Modifying the chemical and physical composition of the teeth can be affected by the solubility of the enamel to acid attacks or mechanical damage during dental function. Natural remineralization offers protection against mechanical damage during dental functions, according to the level of activity of the mouth condition. Good oral hygiene and a low-sugar diet prevent build-up of plaque and reduce the incidence of tooth decay.

The accumulated chemical elements in teeth are regarded as a good indicator of qualitative changes in the modes of nutrition and public water. The restorative materials of resin, porcelain, amalgam, ceramic and other filled material (O, C, Al, Si, Cu, Zn, Ag, Sn, Hg, Ti, Ba, Zr, Si and S) reproduce not only the aesthetic characteristics of the teeth, but also their physical and biological properties which introduce and shift new elements in our teeth.

Carious enamel teeth structure could be a major dental problem due to excess, scarce or absent macro and microelements which are responsible for cases of secondary or recurrent caries, discoloration pulpal inflammation, re-infection and abscess in jaw bone. Moreover, numerous biochemical and genetic functions for trace elements should likely remain to be identified in normal enamel and different kinds of diseases apart of caries to give alternative solutions.

The worked thickness enamel surface has a great degree of mineralization than the free face of occlusion indicating that there is more concentration of minerals in the surface which requires a great hardness for the nature of its function. Strontium and Zinc may enhance remineralization in enamel.

\section{Acknowledgements}

Thanks to Mariel Cardenas Jairo who donated the second premolars of teenagers and Jesus Alvarado for his support.

\section{References}

[1] Gomez, M.E.F. and Campos, A.R. (2009) Histologia y Embriología bucodental. $3^{\mathrm{a}}$ Edición, Editorial Panamericana, Buenos Aires, 274-301, 468.

[2] Ten Cate, A. (1985) Histología Oral. Desarrollo estructura y función. $2^{\circ}$ Edición, Médica Panamericana, Buenos Aires, 65-79.

[3] Barrancos Mooney, L. (1999) Operatoria Dental. Tercera Edición, Editorial Panamericana, Buenos Aires.

[4] Daming, F., Du, Ch., Sun, Z., Lakshminarayanan, R. and Moradian, O.J. (2009) In Vitro Study on the Interaction between the $32 \mathrm{kDa}$ Enamelin and Amelogenin. Journal of Structural Biology, 166, 88-94. http://dx.doi.org/10.1016/j.jsb.2009.01.003

[5] Kaczmarek, E., Brzozowska, T.M. and Miśkowiak, B. (2003) Digital Image Analysis in Dental Research Applied for Treatment of Fissures on Occlusal Surfaces of Premolars. Annals of Biomedical Engineering, 31, 931-936. http://dx.doi.org/10.1114/1.1588653

[6] Rao, A. (2008) Principles and Practice of Pedodontics. 2nd Edition, Jaypee Brothers Medical Publishers, New Delhi, 163-182.

[7] Wen, S.L. (1989) Human Enamel Structure Studied by High Resolution Electron Microscopy. Electron Microscopy Reviews, 2, 1-16. http://dx.doi.org/10.1016/0892-0354(89)90008-7

[8] Fathilah, A.R. and Rahim, Z.H.A. (2008) The Effect of Beverages on the Release of Calcium from the Enamel Surface. Annals of Dentistry University of Malaya, 15, 1-4.

[9] Canizares, F.J., Peso, L.J., Sánchez Quevedo, M.C. and Campos, A. (1987) Microscopia electrónica de barrido de la lesión cariosa incipiente del esmalte dental. Histología Médica, 3, 73-78.

[10] Silverstone, L.M. and Poole, D.F. (1968) Modification of the Histological Appearance of Enamel Caries after Exposure to Saliva and a Calcifying Fluid. Caries Research, 2, 87-96. http://dx.doi.org/10.1159/000259547

[11] Curzon, M.E.J., Spector, P.C., Losee, F.L. and McHugh, W.D. (1976) Trace Elements and Dental Caries. Variation of Strontium Content of Surface Enamel with Geography, Age and Caries. Eastman Dental Center, Rochester, 22 p.

[12] Mansson, A.B. and Whitford, G.M. (1984) Flouride Concentration in the Surface Tooth Enamel of Young Men and Women. Caries Research, 16, 334-339.

[13] Dykstra, M.J. and Reuss, L. (2003) Biological Electron Microscopy: Theory, Techniques and Troubleshooting. Kluwer 
Academic/Plenum, New York. www.springerprotocols.com/Abstract/doi/10.1385/1-59745-144-4:339

[14] Goldstein, J.I., Newbury, D.E., Echlin, P., Joy, D.C., Roming Jr., A.D., Lyman, C.E., Fiori, C. and Lifshin, E. (1992) Scanning Electron Microscopy and X-Ray Microanalysis, Chapter II. Plenum Press, New York. http://dx.doi.org/10.1007/978-1-4613-0491-3

[15] Chew, A., David, E.S. and Waddilove, A.E. (1997) Surface Characterization of Laser Modified Human Tooth Enamel Using Laser Microprobe Mass Spectrometry and Scanning Electron Microscopy. Journal of Analytical Atomic Spectrometry, 12, 1101-1103. http://dx.doi.org/10.1039/a700086c

[16] Glauche, V., Röhrich, J., Bohne, W., Radlanski, R.J., Atar, M., Honda, Y., Yoshida, W., Maeda, H. and Finke, C.H. (2011) Analysis of Tooth Surface Elements by Ion Beam Analysis. Journal of Hard Tissue Biology, 20, 99-106. http://dx.doi.org/10.2485/jhtb.20.99

[17] Bhattacherjee, B. and Sarkar, S. (1999) Trace Elements in Enamel of Sound Primary and Permanent Teeth. Journal of the Indian Society of Pedodontics and Preventive Dentistry, 17, 113-117.

[18] Szostek, K. and Głąb, H. (2001) Trace Elements Concentrations in Human Teeth from a Neolithic Common Grave at Nakonowo (Central Poland). Variability and Evolution, 9, 51-59.

[19] Falla-Sotelo, F.O., Rizzuto, M.A., Tabacnicks, M.H., Added, N. and Barbosa, M.D.L. (2005) Analysis and Discussion of Trace Elements in Teeth of Different Animal Species. Brazilian Journal of Physics, 35, 761-762. http://dx.doi.org/10.1590/S0103-97332005000500010

[20] Anjos, M.J., Barroso, R.C., Pérez, C.A., Braz, D., Moreira, S., Dias, K.R.H.C. and Lopes, R.T. (2004) Elemental Mapping of Teeth Using MU-SRXRF. Proceedings of the 5th International Topical Meeting on Industrial Radiation and Radioisotope Measurement Applications, Bologna, 9-14 June 2002, 569-573.

[21] Markarian, R.A., Quinelato, M.A.M. and Youssef, M. (2005) Analysis and Discussion of Trace Elements in Teeth of Different Animal Species. Brazilian Journal of Physics, 35, 761.

[22] Heijs, S.C., Dietz, W., Norén, J.G., Blanksma, N.G. and Jälevik, B. (2007) Morphology and Chemical Composition of Dentin in Permanent First Molars with the Diagnose MIH. Swedish Dental Journal, 31, 155-164.

[23] Zaichick, V. (2009) Neutron Activation Analysis of Ca, Cl, K, Mg, Mn, Na, P, and Sr Contents in the Crowns of Human Permanent Teeth. Journal of Radioanalytical and Nuclear Chemistry, 281, 41-45. http://dx.doi.org/10.1007/s10967-009-0083-X

[24] Zenóbio, M.A.F., Tavares, M.S.N., Zenóbio, E.G. and Silva, T.A. (2011) Elemental Composition of Dental Biologic Tissue: Study by Means of Different Analytical Technique. Journal of Radioanalytical and Nuclear Chemistry, 289, 161-166. http://dx.doi.org/10.1007/s10967-011-1067-1

[25] Weatherell, J.A. (2001) Composition of Dental Enamel. Oxford Journal Medicine, 31, 115.

[26] Silverstone, L.M. (1977) Remineralization Phenomena. Caries Research, 11, 59-84. http://dx.doi.org/10.1159/000260296

[27] Robinson, C., Hallsworth, A.S. and Kirkham, J. (1984) Distribution and Uptake of Magnesium by Developing Deciduous Bovine Incisor Enamel. Archives of Oral Biology, 29, 479-482. http://dx.doi.org/10.1016/0003-9969(84)90066-9

[28] Larsen, M.J. and Fejerskov, O. (1989) Chemical and Structural Challenges in Remineralization of Dental Enamel Lesions. Scandinavian Journal of Dental Research, 97, 285-296.

[29] Sarkar, S. and Roychoudhary, P. (2004) Leach Out of Inorganic and Trace Elements at the Time of Etching. Journal of the Indian Society of Pedodontics and Preventive Dentistry, 22, 76-81.

[30] Yamazaki, H. and Margolis, H.C. (2008) Enhanced Enamel Remineralization under Acidic Condition in Vitro. Journal of Dental Research, 87, 569-574. http://dx.doi.org/10.1177/154405910808700612

[31] Zhang, L.L., Li, J.Y., Zhou, X.D., Cui, F.Z. and Wei, L. (2009) Chemical and Crystallographic Study of Remineralized Surface on Initial Carious Enamel Treated with Galla Chinensis. Scanning, 31, 236-245. http://dx.doi.org/10.1002/sca.20176

[32] Swain, M.I.V. and Xue, J. (2009) State of the Art of Micro-CT Applications in Dental Research. International Journal of Oral Science, 1, 177-188. http://dx.doi.org/10.4248/IJOS09031

[33] Pamukcu, G.E., Mehmet, E.Y., Fikrettin, S.M.M., Yazic, A.A. and Rizvanov, G.B. (2011) Effect of Dental Materials Calcium Hydroxide-Containing Cement, Mineral Trioxide Aggregate and Enamel Matrix Derivative on Proliferation and Differentiation of Human Tooth Germ Stem Cells. Journal of Endodontics, 37, 650-656. http://dx.doi.org/10.1016/j.joen.2011.02.008

[34] Bodier, H.P., Stuer, P., Meyer, J.M., Bigerard, L. and Cuisiner, F.J. (2000) High-Resolution Electron Ion Microscopic Study of the Relationship between Human Enamel and Dentin Crystals at de Dentin Enamel Junction. Cell and Tissue Research, 301, 389-395. 
[35] Yavenes, I. (1995) Study of the Concentration and Stability of Dental Topical Fluorides. Journal of Dental Research, 74, 901. http://jdr.sagepub.com

[36] Riyat, M. and Sharma, D.C. (2009) Analysis of 35 Inorganic Elements in Teeth in Relation to Caries Formation. Biological Trace Element Research, 129, 126-129. http://dx.doi.org/10.1007/s12011-008-8305-6

[37] Lara, M.V.Z., Machado, M.P., Vaz, R.R. and Mota, J.M.L.F. (2004) Comparison of Cervical Adaptation in Class II Aesthetic and Metallic Restorations: Dental Materials-FOUFMG-Belo Horizonte. Journal of Applied Oral Science, 12. http://www.scielo.br/scielo.php?pid=S1678-77572004000500005\&script=sci_arttext

[38] Drea, W.S. (1935) Spectral Analysis of Dental Tissue for Trace Elements. Journal of Dental Research, 15, 403-406. http://dx.doi.org/10.1177/00220345350150060401

[39] Shashikiran, N.D., Subba Reddy, V.V. and Hiremath, M.C. (2007) Estimation of Trace Elements in Sound and Carious Enamel of Primary and Permanent Teeth by Atomic Absorption Spectrophotometry: An in Vitro Study. Indian Journal of Dental Research, 18, 157-162. http://dx.doi.org/10.4103/0970-9290.35824

[40] Lowater, F. and Margaret, M.M. (1937) Chemical Composition of Teeth: Spectographic Analysis. British Dental Journal, 61, 837-841.

[41] Sendur, A. (1998) Magnesium Content in the Hard Dental Tissues. Czasopismo Stomatologiczne, 51, 785-790.

[42] Grzegorz, A.P., Gutowska, B.I., Machoya, S.Z. and Gutowska, M.P. (2009) Changes in Mineral Composition of Human Primary Dentition. Research Report Fluoride, 42, 23-28.

[43] Borggreven, J.M.P.M., Driessens, F.C.M. and Van Dijk, J.W.E. (1986) Dissolution and Precipitation Reactions in Human Tooth Enamel under Weak Acid Conditions. Archives of Oral Biology, 31, 139-144. http://dx.doi.org/10.1016/0003-9969(86)90118-4

[44] Imfeld, T. (1996) Dental Erosion Definition, Classification and Links. European Journal of Oral Sciences, 104, 151155. http://dx.doi.org/10.1111/j.1600-0722.1996.tb00063.x

[45] Moss, S.J. (1988) Dental Erosion. International Dental Journal, 48, 529-539.

[46] Cole, A.S., Eastoe, J.E., McGivan, J., Hayes, M.I. and Smillie, A.C. (1988) Biochemistry and Oral Biology. 2nd Edition, Wright, Britain.

[47] Frysh, H. (1995) Chemistry of Bleaching. In: Goldstein, R.E. and Garber, D.A., Eds., Complete Dental Bleaching, Quintessence Book, Chicago, 25-32.

[48] Gontijo, L., Almeida, C.R. and Gomes, B.P.B. (2007) Dental Enamel Around Fixed Orthodontic Appliances after Fluoride Varnish Application. Brazilian Dental Journal, 18, 49-53.

[49] Daculsi, G., Bouler, J.-M. and LeGeros, R.Z. (1997) Adaptative Crystal Formation in Normal and Pathological Calcifications in Synthetic Calcium Phosphate and Related Biomaterials. International Review of Cytology, 172, 129-191.

[50] Alejandro, F.A., Romo, C.D.S., Perez, R.M.J., Solano, V.G., Flores, A.J.C., Gaitán F.C.A., Reyes, V.E., Yusa, C. and Mazuoka, I.D. (2012) Comparación de técnicas fotopolimerización para disminuir la contracción de las resinas compuestas. Luz Médica. Universidad Autonóma de Aguascalientes, Centro de Ciencias de la Salud, Departamento de Estomatología, Cd Universitaria, Aguascalientes, 11.

[51] Jackson III, G.H., Chem, B.S. and Law, J.D. (1991) Quantitative Analysis of Hg, Ag, Sn, Cu, Zn and Trace Elements in Amalgam Removed from an Abutment Tooth Underneath a Gold Alloy Bridge That Had Been in Vivo for Nine Plus Years. Experientia, 47, 9-22.

[52] Santana, T.D. and Vasconcelos, J.K.O.S. (2004) Etiologic Factors Reported to Dental Sensitivity Happens in Adhesive Aesthetic Dentistry. Journal of Applied Oral Science, 12. http://www.scielo.br/scielo.php?pid=S1678-77572004000500005\&script=sci_arttext. 
Scientific Research Publishing (SCIRP) is one of the largest Open Access journal publishers. It is currently publishing more than 200 open access, online, peer-reviewed journals covering a wide range of academic disciplines. SCIRP serves the worldwide academic communities and contributes to the progress and application of science with its publication.

Other selected journals from SCIRP are listed as below. Submit your manuscript to us via either submit@scirp.org or Online Submission Portal.
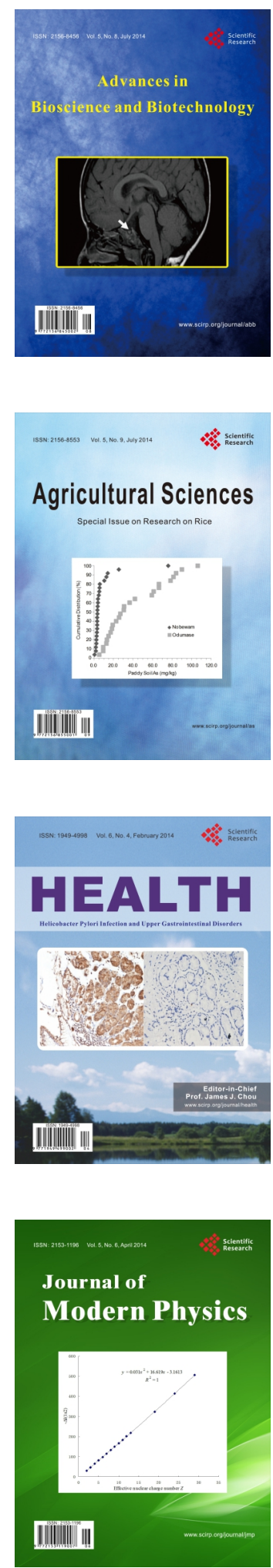
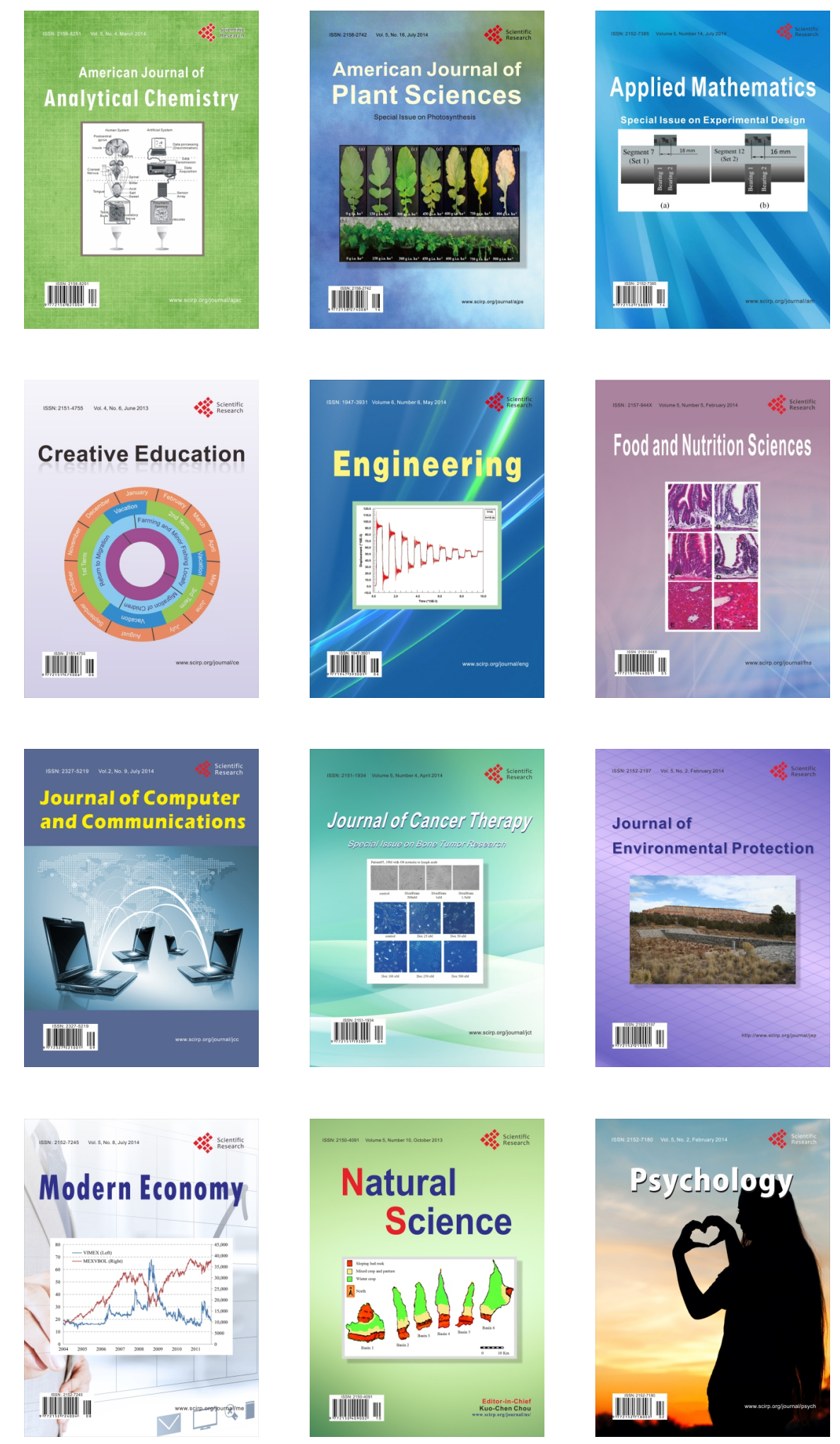